\title{
Modelling public-transport users' perception of out-of-vehicle times using cumulative prospect theory and fuzzy logic
}

\author{
S. J. Chowdhury \& A. Ceder \\ Faculty of Engineering, Department of Civil and Environmental \\ Engineering, University of Auckland, New Zealand
}

\begin{abstract}
Out-of-vehicle times for public-transport users have been shown to be perceived as being more onerous than in-vehicle time when making transfers. The objective of the present study is to determine the effects of uncertainty, in out-ofvehicle times during transfers, on users' willingness to use transfer routes. A user preference survey was conducted at two major public-transport terminals in Auckland, New Zealand. The survey data was modelled using the cumulative prospect theory and fuzzy logic. To the authors' knowledge, this study provides for the first time in literature a comparison between the two cognitive models. Analysis suggested that both models are capable of representing transit users' out-of-vehicle behaviour when making transfers. The results showed that for all trip attributes, except for comfort, transit users' exhibited greater preference for the transfer route with less uncertainty in the out-of-vehicle times. For comfort, defined as the wait time for an available seat at stations, transit users' displayed risk-taking characteristics.

Keywords: travel behaviour, public transport, transfers, cumulative prospect theory (CPT), fuzzy logic.
\end{abstract}

\section{Introduction}

Quality of transfer connectivity plays an important role in attracting potential public transport (PT) users and sustaining the satisfaction of existing users [1]. Iseki and Taylor [2] explains that although out-of-vehicle times have been recognised to be a crucial element in PT users' satisfaction, there has been a limited number of studies on the effects of out-of-vehicle trip attributes and 
transfer facilities on PT ridership. As a result, there exists a lack in complete understanding of how out-of-vehicle trip attributes affect PT users' travel behaviour and thus the effect of these attributes on ridership of transfer routes [2]. The study contributes to existing knowledge by providing decision makers with an understanding of the effects quality of out-of-vehicle trip attributes have on PT users' intention to use transfer routes. A survey was conducted in two transport centres in Auckland, New Zealand. The survey data was modelled using the cumulative prospect theory (CPT) and fuzzy logic. To the authors' knowledge, for the first time in literature, the study provides a comparison of the two commonly used cognitive models.

\section{Literature review}

\subsection{Out-of-vehicle trip attributes}

Access to and between stations and stops have been recognised to be key elements in PT travel. Reducing perceived walking and waiting times for transfers was shown to substantially increase the attractiveness of PT [2]. Perceived waiting time is dependent on waiting conditions such as security and safety, reliability of connection and comfort [2]. Reducing the uncertainty of waiting time was shown to improve passenger satisfaction and thus to increase ridership [3]. Personal safety at terminals has been revealed to be the most important factor in travellers' decision to use PT [4, 5]. Missed connections and delays are shown to cause anxiety to the user [6]. Comfort at transfer terminals has been identified to be a determining factor in PT users' perceived ease of making a transfer [1]. Perceived walking distance and time has also been shown to be substantially longer than actual walking time. Presence of escalators, longer ramps and same-level interchange has been shown to mitigate the perceived inconvenience caused by having to walk for transfers [7].

\subsection{Cognitive models}

When modelling mode and route choice, in travel behaviour studies, it has been a common practice to assume that travellers have perfect knowledge about their choices and make rational decisions based on utility maximisation [8]. Discrete choice models derived using expected utility theory (EUT) and random utility theory (RUT) have been frequently adopted to analyse choice in travel behaviour studies $[7,9,10]$. An increasing number of route choice studies have been challenging the assumption of travellers' absolute rationality by showing evidence of violations of EUT $[8,11]$. Statistical models using the assumption of utility maximisation overlook the fact that human decision making is approximate rather than precise [12, 13].

\subsection{Fuzzy logic}

Traditional crisp choice models are not capable of incorporating vagueness in decision making [14]. Fuzzy logic, first introduced by Zadeh [15], enables the 
formation of logical statements to compute vagueness. Using the concept of “approximate reasoning”, fuzzy logic makes it possible to model imprecision in human reasoning. It is evident from a number of route and mode choice studies that fuzzy logic is capable of modelling ambiguity in PT users' perception and appraisal of trip attributes $[13,14,16]$. Each fuzzy logic system can be divided into three stages: fuzzification, fuzzy inference and defuzzification. Figure 1 shows the link among the stages and the input and output of each stage.

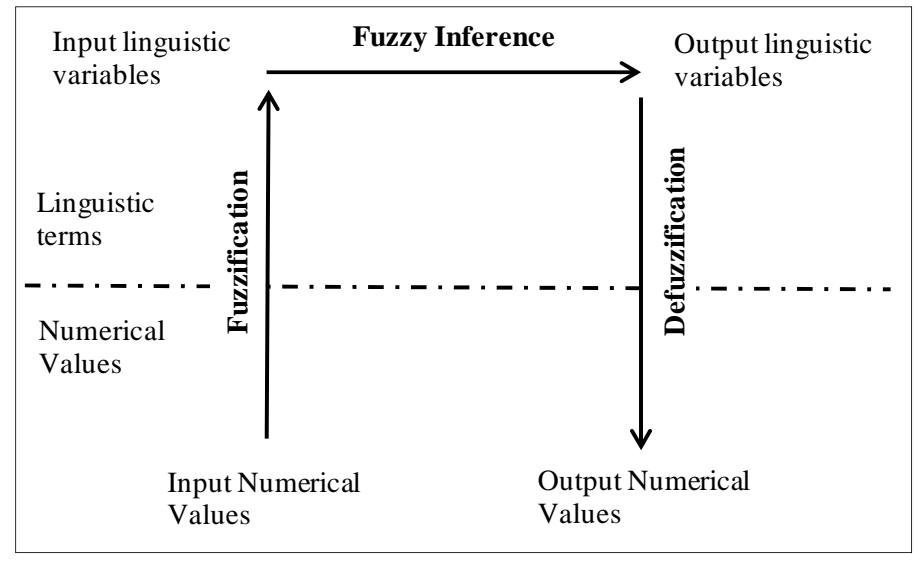

Figure 1: $\quad$ Fuzzy logic systems.

\subsection{Cumulative prospect theory}

In 1992, Kahneman and Tversky [17] introduced the cumulative prospect theory (CPT), an extension of their prospect theory model. The central feature of CPT is that it is able to model diminishing sensitivity in decision making [18]. The Sshaped value function represents diminishing sensitivity. CPT assumes that choices are evaluated in two steps: an initial phase of editing and a subsequent phase of evaluation [19]. Individuals are risk averse when outcomes $\left(x_{i}\right)$ are framed as gains and risk seeking when outcomes $\left(x_{i}\right)$ are framed as losses, relative to the reference point $\left(x_{O}\right)$ [17]. The evaluation phase is composed of a value function and a probability weighting function [19]. It has been found in numerous experimental data that the weighting function is relatively sensitive to changes in probability near the end points 0 and 1 , but relatively insensitive to changes in probability in the middle region. For explanation of CPT notations, refer to the study by Xu et al. [8].

Van de Kaa [20] reviewed a large range of travel-related studies and concluded that CPT is more capable of accurately modelling travellers' perception of trip attributes and route choice than traditional utility theories such as EUT. 


\section{Survey of public-transport users}

\subsection{Trip attributes and questionnaire design}

Trip attributes selected to measure PT users' perception of out-of-vehicle times are: transfer delay time (DT), transfer waiting time (TWT $)_{1}$ ) and transfer walking time $\left(\mathrm{TWT}_{2}\right)$. PT users' perception of personal safety and comfort was measured for a given $\mathrm{TWT}_{1}$.

High quality transfer connections have the potential to save journey time for travellers [21]. Participants of the survey were presented with a hypothetical case of a direct route journey time equal to 45-50 minutes (Scenario 3) and two transfer routes (Scenario 1 and 2) with equal travel time saving of 15-20min in comparison to the direct route. Three cases were presented for each of the out-ofvehicle trip attributes. In each case, one transfer route scenario was designed to be perceived as being "less conservative" and the other to be "more conservative". The cases were designed in accordance with past route choice studies [8, 19, 22] which considered uncertainty in decision making. Personal security was defined as the users' probable waiting time to reach a security guard when feeling unsafe. Comfort was defined as the probable waiting time to get an available seat in the station [23]. Scenarios for personal security and comfort were measured under the assumption of $\mathrm{TWT}_{1}$ being 10 minutes. Participants were given multi-choice questions to determine the reference point (RP) of each trip attribute for the CPT analysis [20].

\subsection{Survey locations and limitations}

Britomart Transport Centre and Newmarket Train Station were chosen to be the two survey locations. Britomart provides a link between the main bus, train, and ferry services of the Auckland Region. Newmarket Train Station is a key junction in the Auckland railway network. The station caters to the Southern and Western lines. Site observations at Newmarket Train Station during the morning peak period revealed the possibility of intermodal (train/bus) transfers due to bus stops with high frequency services (on average every 10 minutes) located near the station.

It is to be noted that the sample represents a random sample of only the two stations. To generalized findings of this study, surveys at other stations at other times of the day may be done.

\section{Results and modeling}

\subsection{Analysis of survey data}

Prior to modelling the survey data using CPT and fuzzy logic, the data was assessed for influence of site specific characteristics. Chi-squared test was used to verify that the responses are independent of the two stations. The results 
confirmed that the data from the two stations are independent of the site and can be combined to form one data set.

\subsection{Modelling using CPT}

Van de Kaa [20] suggested that the parameters of CPT suggested by Kahneman and Tversky [17] offer the best functional description of travel choice under uncertainty in a wider variety of contexts. The present study uses eqn. (1) to eqn. (6) ( $\alpha=\eta=0.88, \lambda=2.25, \gamma=0.61, \delta=0.69)$ to calculate the cumulative prospect values for the transfer route scenarios $[8,19,22]$.

$$
\begin{aligned}
& v\left(\Delta x_{i}\right)=\left\{\begin{array}{c}
x^{\alpha} \text { if } x \geq 0 \\
-\lambda(-x)^{\beta} \text { if } x<0
\end{array}\right. \\
& \pi^{+}\left(p_{i}\right)=w^{+}\left(p_{i}+\cdots+p_{n}\right)-w^{+}\left(p_{i+1}+\cdots+p_{n}\right) ; 0 \leq i \leq n \\
& \pi^{-}\left(p_{-j}\right)=w^{-}\left(p_{-m}+\ldots+p_{-j}\right)-w^{-}\left(p_{m}+\cdots+p_{-j-1}\right) ; m \leq-j<0 \\
& w^{+}\left(p_{i}\right)=p_{i}^{\gamma} /\left[p_{i}^{\gamma}+\left(1-p_{i}\right)^{\gamma}\right]^{1 / \gamma} \\
& w^{-}\left(p_{i}\right)=p_{i}^{\delta} /\left[p_{i}^{\delta}+\left(1-p_{i}\right)^{\delta}\right]^{1 / \delta} \\
& u\left(x_{i,} p_{i}\right)=\sum_{i=0}^{n} v\left(\Delta x_{i}\right) \pi^{+}\left(p_{i}\right)+\sum_{j=-m}^{-1} v\left(\Delta x_{i}\right) \pi^{-}\left(p_{-j}\right)
\end{aligned}
$$

The weighted sum approach was undertaken to derive the RP values for each trip attribute from the survey data. Table 1 gives the RP values, the cumulative prospect values and the corresponding proportion of participants willing to use the transfer routes for each trip attribute. Cumulative prospect values were calculated using two other RP values (+/- 5 minutes) to determine the degree of fluctuation in the values with respect to the participants' preference [8].

The verification process of the model was undertaken by randomly dividing the data set into two sets: 200 data-points (Set A) and 100 data-points (Set B). This division created a data set, Set A, which was used to develop the CPT model and a separate data set, Set B, which was used to validate the output of the model. A chi-squared test was used to determine any evidence of significant difference between the proportion of responses for the 200 data points and the 100 data points. The chi-squared values attained showed that the there is no statistical evidence of significant difference between the two data sets.

\subsection{Analysis using fuzzy logic}

\subsubsection{Fuzzification}

Fuzzification is the process of defining "crisp" inputs as fuzzy linguistic variables by associating the input with membership values [24]. 
Table 1: Cumulative prospect values and proportion of responses for each RP.

\begin{tabular}{|c|c|c|c|c|c|c|}
\hline \multirow[t]{2}{*}{ TWT $_{1}$} & \multicolumn{2}{|c|}{ Case A } & \multicolumn{2}{|c|}{ Case B } & \multicolumn{2}{|c|}{ Case $\mathrm{C}$} \\
\hline & S1 & $\mathrm{S} 2$ & S1 & S2 & S1 & $\mathrm{S} 2$ \\
\hline & \multicolumn{6}{|c|}{ Cumulative Prospect Value } \\
\hline 4 & -12.28 & -14.96 & -8.69 & -7.65 & -10.34 & -7.65 \\
\hline 9 & -3.52 & -8.81 & -3.43 & -1.90 & -4.67 & -1.90 \\
\hline 14 & 1.49 & -3.42 & 2.14 & 3.96 & 1.41 & 3.96 \\
\hline Proportion & $67.7 \%$ & $23.7 \%$ & $38.3 \%$ & $53.7 \%$ & $34.3 \%$ & $56.3 \%$ \\
\hline $\mathbf{T W T}_{2}$ & \multicolumn{2}{|c|}{ Case A } & \multicolumn{2}{|c|}{ Case B } & \multicolumn{2}{|c|}{ Case $\mathrm{C}$} \\
\hline & \multicolumn{6}{|c|}{ Cumulative Prospect Value } \\
\hline 1.5 & -9.12 & -7.90 & -9.02 & -7.45 & -7.90 & -5.83 \\
\hline 6.5 & -1.55 & -0.40 & -2.66 & 0.31 & -1.67 & 1.49 \\
\hline 11.5 & 3.72 & 4.28 & 3.23 & 4.70 & 4.28 & 5.29 \\
\hline Proportion & $37.0 \%$ & $55.0 \%$ & $32.0 \%$ & $60.0 \%$ & $22.7 \%$ & $69.3 \%$ \\
\hline \multirow[t]{2}{*}{ DT } & \multicolumn{2}{|c|}{ Case A } & \multicolumn{2}{|c|}{ Case B } & \multicolumn{2}{|c|}{ Case C } \\
\hline & \multicolumn{6}{|c|}{ Cumulative Prospect Value } \\
\hline 2.5 & -8.07 & -7.04 & -10.79 & -10.71 & -9.36 & -8.58 \\
\hline 7.5 & -2.26 & 0.57 & -5.01 & -1.79 & -3.23 & -1.62 \\
\hline 12.5 & 3.36 & 4.76 & 0.38 & 3.44 & 2.92 & 3.87 \\
\hline Proportion & $22.0 \%$ & $70.0 \%$ & $31.7 \%$ & $59.7 \%$ & $30.7 \%$ & $61.0 \%$ \\
\hline \multirow[t]{2}{*}{ Comfort } & \multicolumn{2}{|c|}{ Case $\mathbf{A}$} & \multicolumn{2}{|c|}{ Case B } & \multicolumn{2}{|c|}{ Case $\mathrm{C}$} \\
\hline & \multicolumn{6}{|c|}{ Cumulative Prospect Value } \\
\hline 2.5 & -14.62 & -17.38 & -10.79 & -9.35 & -16.29 & -11.00 \\
\hline 4.5 & -11.48 & -14.10 & -8.15 & -7.58 & -15.67 & -7.58 \\
\hline 6.5 & -8.20 & -9.47 & -6.05 & -4.81 & -8.96 & -4.81 \\
\hline Proportion & $53.3 \%$ & $38.3 \%$ & $51.0 \%$ & $40.3 \%$ & $21.0 \%$ & $71.0 \%$ \\
\hline Security & \multicolumn{2}{|c|}{ Case $\mathbf{A}$} & \multicolumn{2}{|c|}{ Case B } & \multicolumn{2}{|c|}{ Case C } \\
\hline & \multicolumn{6}{|c|}{ Cumulative Prospect Value } \\
\hline 1 & -13.71 & -10.40 & -13.71 & -2.58 & -15.43 & -9.19 \\
\hline 3 & -10.75 & -7.00 & -10.75 & -5.05 & -12.48 & -5.76 \\
\hline 5 & -8.54 & -3.90 & -8.54 & -2.58 & -10.12 & -2.57 \\
\hline Proportion & $37.7 \%$ & $54.3 \%$ & $24.7 \%$ & $67.3 \%$ & $21.0 \%$ & $71.0 \%$ \\
\hline
\end{tabular}

The membership function expresses the degree that an element of the universal set belongs to the fuzzy set. A fuzzy set can take any value within the closed interval $[0,1]$ [16]. For the present study, a triangular shape has been adopted as shown in Figure 2 [25]. Each trip attribute (input) and difference in weighted time between the two transfer route scenarios (WT) (input) were classified into three groups: low, moderate and high. PT users' preference for a transfer route (output) was grouped into seven ridership categories: A, B, C, D, $\mathrm{E}, \mathrm{F}, \mathrm{G}$ and $\mathrm{H}$.

\subsubsection{Fuzzy inference}

Fuzzy inference handles the degree of approximate match between the input and the antecedent of the rule. The number of fuzzy rules is dependent on the combination of input variables [24]. The data set was divided into two equal data sets (Set A and B), each with 150 data-points. A chi-squared test was undertaken to determine independence of the two data sets. Results showed that the two data sets are independent. Set A was used to derive the fuzzy rules. 


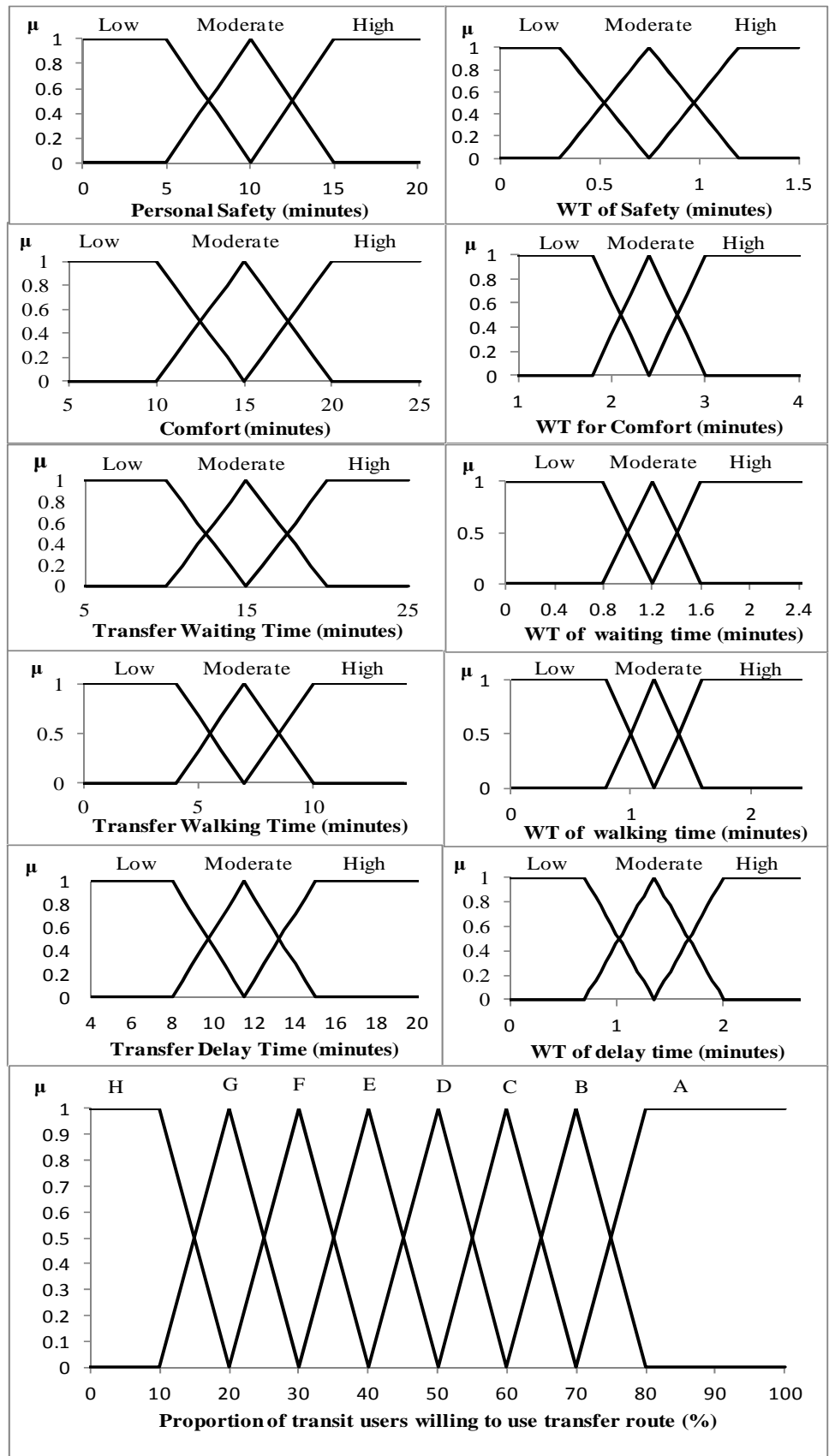

Figure 2: $\quad$ Fuzzy sets for input and output variables. 
The proportion of participants who selected the direct route was excluded in development of the fuzzy rules. The model reflects participants' preference for only the transfer route scenarios, with the output of the fuzzy system being proportion of users choosing Scenario 1 and the remainder is the proportion of users choosing Scenario 2. Each fuzzy rule has two inputs, quality of the trip attribute and WT. The general format for the fuzzy rules is as follows:

IF [trip attribute] is $\left[X_{T A}\right]$ and $\left[\Delta\right.$ weighted time] is $\left[X_{W T}\right]$, THEN ridership is $\left[Y_{R}\right]$.

The entire fuzzy inference process can be represented with an example as follows:

Scenario 1 (DT): 80\% probability of waiting for 3 minutes when the vehicle is delayed and $20 \%$ probability of waiting for 12 minutes when the vehicle is delayed.

Based on Figure 2, the input data DT and WT are fuzzified. Based on the fuzzified input data, the corresponding fuzzy rules were used. The max-min composition method is applied for making the fuzzy inference. This procedure is shown in Table 2 [24, 26].

Table 2: $\quad$ Fuzzification and fuzzy inference example

\begin{tabular}{|c|c|c|c|c|}
\hline \multicolumn{5}{|c|}{ Fuzzification of input data for Scenario 1} \\
\hline \multicolumn{2}{|c|}{ Input variable } & Input data & $\begin{array}{c}\text { Fuzzified } \\
\text { category }\end{array}$ & Membership grade \\
\hline \multirow{3}{*}{\multicolumn{2}{|c|}{ Delay Time (DT) }} & 3 minutes & Low & 1.0 \\
\hline & & 12 minutes & Moderate & 0.88 \\
\hline & & & High & 0.12 \\
\hline \multirow{2}{*}{\multicolumn{2}{|c|}{$\begin{array}{l}\text { Difference in } \\
\text { weighted times } \\
\text { (WT) }\end{array}$}} & \multirow[t]{2}{*}{1.1} & Low & 0.38 \\
\hline & & & \multirow[t]{2}{*}{ Moderate } & 0.62 \\
\hline \multicolumn{4}{|c|}{ Fuzzy Inference for Scenario 1} & \\
\hline & \multicolumn{2}{|c|}{ Input data } & & \\
\hline $\begin{array}{l}\text { Rule } \\
\text { no. }\end{array}$ & DT & WT & Ridership & Max-min composition \\
\hline 9 & $\begin{array}{l}\text { Low } \\
(1.0)\end{array}$ & $\begin{array}{l}\text { Low } \\
(0.38) \\
\end{array}$ & $\mathrm{F}$ & Min $(1.0,0.38)=0.38$ \\
\hline 3 & $\begin{array}{l}\text { Low } \\
(1.0)\end{array}$ & $\begin{array}{l}\text { Moderate } \\
(0.62)\end{array}$ & G & Min $(1.0,0.62)=0.62$ \\
\hline 1 & $\begin{array}{c}\text { Moderate } \\
(0.88)\end{array}$ & $\begin{array}{l}\text { Moderate } \\
(0.62)\end{array}$ & G & Min $(0.88,0.62)=0.62$ \\
\hline 2 & $\begin{array}{l}\text { High } \\
(0.12)\end{array}$ & $\begin{array}{l}\text { Moderate } \\
(0.62)\end{array}$ & $\bar{G}$ & Min $(0.12,0.62)=0.12$ \\
\hline 8 & $\begin{array}{l}\text { High } \\
(0.12)\end{array}$ & $\begin{array}{l}\text { Low } \\
(0.38)\end{array}$ & $\mathrm{F}$ & Min $(0.12,0.38)=0.12$ \\
\hline 7 & $\begin{array}{l}\text { Moderate } \\
(0.88)\end{array}$ & $\begin{array}{l}\text { Low } \\
(0.38)\end{array}$ & $\mathrm{F}$ & Min $(0.88,0.38)=0.38$ \\
\hline & & & & $\begin{array}{l}\text { F: } \operatorname{Max}(0.38,0.12,0.38)=0.38 \\
G: \operatorname{Max}(0.62,0.12,0.62)=0.62\end{array}$ \\
\hline
\end{tabular}




\subsubsection{Defuzzification}

Defuzzification is the final stage of the fuzzy systems. The process involves converting the fuzzy inference outputs into a crisp value. A common approach is the centre of gravity method. The expression used to derive the crisp output value $y^{*}$ is shown in eqn. (7) [26].

$$
y *=\frac{\int \mu(y) y d y}{\int \mu(y) d y}
$$

For the example above, the resulting ridership levels from the fuzzy inference system was F (0.45) and G (0.55). The centre of gravity calculation is as follows: $C G$

$=\frac{\left.\left\{\int_{10}^{16.2}(0.1 y-1) y d y+\int_{16.2}^{23.8} 0.62 y d y+\int_{23.8}^{26}(-0.1 y+3) y d y+\int_{26}^{36} 0.38 y d y+\int_{36}^{40}(-0.1 y+4) y d y\right)\right\}}{\left\{\int_{10}^{16.2}(0.1 y-1) d y+\int_{16.2}^{23.8} 0.62 d y+\int_{23.8}^{26}(-0.1 y+3) d y+\int_{26}^{36} 0.38 d y+\int_{36}^{40}(-0.1 y+4) d y\right\}}$

Of the proportion of transits users who were willing to use transfer routes, 24\% preferred Scenario 1 and 76\% preferred Scenario 2.

\subsubsection{Verification of model}

The outputs of the model were verified using Set B. A chi-squared test was used to determine any evidence of significant difference between the proportions of respondents selecting each scenario given by the fuzzy system and the survey data of Set B. The analysis revealed that there is no statistical evidence of significant difference. Table 3 gives the results of the analysis.

\subsubsection{Final model}

The final model was developed using the complete survey data set of 300 datapoints. Only the fuzzy rules of the system needed to be updated. Table 4 provides a sample of the new 45 fuzzy rules for Scenario 1.

The outputs of the fuzzy system for the complete set were compared with the actual responses given by participants to assess the final model. The analysis revealed no statistical evidence of significant difference between the model outputs and the actual responses attained from the survey data.

\section{Discussion and conclusion}

The present study aims to provide researchers and practitioners with a better understanding of the effects uncertainty in out-of-vehicle times have on PT users' decision to use transfer routes. The results of the analysis has shown that for all trip attributes, except for comfort, transit users' exhibited greater preference for the scenario that was perceived to be "more conservative" (less uncertainty) despite a higher probability of shorter out-of-vehicle time in the "less conservative" scenario. In the cases with high WT, the difference between the proportions of users choosing the two transfer-route scenarios was seen to be greater than the cases with smaller WT. Findings suggested that transit users' perceive an attractive transfer route to be one that has a lower variability in outof-vehicle times. 
Table 3: $\quad$ Comparison between model output and survey data.

\begin{tabular}{|c|c|c|c|c|c|}
\hline $\begin{array}{c}\text { Trip } \\
\text { Attribute }\end{array}$ & Case & Scenario & $\begin{array}{l}\text { Fuzzy Output } \\
\text { (Set B) }\end{array}$ & $\begin{array}{c}\text { Survey } \\
\text { Data } \\
\text { (Set B) }\end{array}$ & $\begin{array}{c}\text { Chi-squared/ } \\
\text { p-value }\end{array}$ \\
\hline \multirow{6}{*}{$\begin{array}{l}\text { Transfer } \\
\text { waiting time }\end{array}$} & \multirow[t]{2}{*}{ A } & S1 & 97 & 107 & \multirow[t]{6}{*}{$1.773 / 0.183$} \\
\hline & & S2 & 42 & 32 & \\
\hline & \multirow[t]{2}{*}{ B } & S1 & 56 & 54 & \\
\hline & & $\mathrm{S} 2$ & 84 & 86 & \\
\hline & \multirow[t]{2}{*}{ C } & S1 & 56 & 49 & \\
\hline & & S2 & 83 & 90 & \\
\hline \multirow{6}{*}{$\begin{array}{l}\text { Transfer } \\
\text { walking time }\end{array}$} & \multirow[t]{2}{*}{ A } & S1 & 56 & 59 & \multirow[t]{6}{*}{$0.191 / 0.662$} \\
\hline & & $\mathrm{S} 2$ & 84 & 81 & \\
\hline & \multirow[t]{2}{*}{ B } & S1 & 56 & 54 & \\
\hline & & $\mathrm{S} 2$ & 84 & 86 & \\
\hline & \multirow[t]{2}{*}{ C } & S1 & 28 & 33 & \\
\hline & & S2 & 112 & 107 & \\
\hline \multirow{6}{*}{$\begin{array}{l}\text { Transfer delay } \\
\text { time }\end{array}$} & \multirow[t]{2}{*}{ A } & S1 & 28 & 37 & \multirow[t]{6}{*}{$1.041 / 0.307$} \\
\hline & & $\mathrm{S} 2$ & 112 & 103 & \\
\hline & \multirow[t]{2}{*}{ B } & S1 & 42 & 47 & \\
\hline & & S2 & 97 & 92 & \\
\hline & \multirow[t]{2}{*}{ C } & S1 & 42 & 41 & \\
\hline & & S2 & 98 & 99 & \\
\hline \multirow[t]{6}{*}{ Comfort } & \multirow[t]{2}{*}{ A } & S1 & 82 & 83 & \multirow[t]{6}{*}{$0.175 / 0.675$} \\
\hline & & $\mathrm{S} 2$ & 55 & 54 & \\
\hline & \multirow[t]{2}{*}{ B } & S1 & 68 & 73 & \\
\hline & & $\mathrm{S} 2$ & 68 & 63 & \\
\hline & \multirow[t]{2}{*}{ C } & S1 & 27 & 29 & \\
\hline & & S2 & 110 & 108 & \\
\hline \multirow[t]{6}{*}{ Safety } & \multirow[t]{2}{*}{$\bar{A}$} & S1 & 55 & 50 & \multirow[t]{6}{*}{$0.071 / 0.789$} \\
\hline & & S2 & 82 & 87 & \\
\hline & \multirow[t]{2}{*}{ B } & S1 & 27 & 34 & \\
\hline & & S2 & 110 & 103 & \\
\hline & \multirow[t]{2}{*}{$\mathrm{C}$} & S1 & 27 & 29 & \\
\hline & & S2 & 110 & 108 & \\
\hline
\end{tabular}

Table 4: $\quad$ Fuzzy rules (sample set) for 300 data-points.

\begin{tabular}{|cl|}
\hline Scenario 1 & \\
\hline $\begin{array}{c}\text { Rule no. } \\
1\end{array}$ & Transfer waiting time (TWT $\mathbf{1}$ ) \\
2 & IF [TWT $_{1}$ ] is [high] and [WT] is [low] THEN [ridership] is [B]. \\
3 & IF [TWT $_{1}$ ] is [moderate] and [WT] is [low] THEN ridership is [B]. \\
. & IF [TWT ${ }_{1}$ ] is [low] and [WT] is [low] THEN ridership is [B]. \\
& - \\
43 & Personal Security \\
44 & IF [safety] is [high] and [WT] is [low] THEN ridership is [G]. \\
45 & IF [safety] is [low] and [WT] is [low] THEN ridership is [G]. \\
\hline
\end{tabular}


For comfort, transit users' displayed risk-taking characteristics when the waiting time for an available seat was less than 5 minutes. Such findings support the study by Eboli and Mazzulla [4] which discussed that although comfort has been identified as an important factor in service satisfaction, it is less important in the PT user's decision process than other service factors. Practitioners need to focus on methods of improving consistency in out-of-vehicle times to increase ridership of transfer routes.

Analysis of the data have shown that the two cognitive models, CPT and fuzzy logic, are capable of representing PT users' out-of-vehicle behaviour when making transfers. The cumulative prospect values were able to accurately reflect PT users' preference for the various transfer route scenarios. As the difference between the cumulative prospect values for the two transfer scenarios increased, the difference in the proportion of participants' preference also increased, with users favouring the higher cumulative prospect value scenario. Analysis revealed no statistical evidence of significant difference between outputs from the fuzzy system developed and survey data. Therefore, PT users' out-of-vehicle travel behaviour can be modelled using either CPT or fuzzy logic.

\section{References}

[1] Guo, Z. andWilson, N.H.M., Assessing the cost of transfer inconvenience in public transport systems: A case study of the London Underground. Transporation Research Part A: Policy and Practice, 45(2), pp. 91-104, 2011.

[2] Iseki, H. andTaylor, B.D., Not All Transfers Are Created Equal: Towards a Framework Relating Transfer Connectivity to Travel Behaviour. Transport Reviews, 29(6), pp. 777-800, 2009.

[3] McCord, M.M., Wirtz, J.,and Mishalani, R.G., Passenger waiting time perceptions at bus stops. Journal of Public Transportation, 9(2), pp. 89106, 2006.

[4] Eboli, L. and Mazzulla, G., Performance indicators for an objective measure of public transport service quality. European Transport, 51, pp. 121, 2012.

[5] Atkins, S.T., Personal security as a transport issue: a state-of-the-art review. Transportation Reviews, 10(2), pp. 111-125, 1990.

[6] Cheng, Y.-H., Exploring passenger anxiety associated with train travel Transportation, 37(6), pp. 875-896, 2010.

[7] Guo, Z. andWilson, N.H.M., Assessment of the Transfer Penalty for Transit Trip. Transportation Research Record No. 1872, pp. 10-18, 2004.

[8] $\mathrm{Xu}, \mathrm{H} .$, Zhou, J., and $\mathrm{Xu}, \mathrm{W} ., \mathrm{A}$ decision making rule for modeling travelers' route choice behaviour based on cumulative prospect theory. Transport Research Part C, 19(2), pp. 218-228, 2011.

[9] O’Fallon, C., Sullivan, C.,and Hensher, D.A., Constraints affecting mode choice by morning car commuters. Transport Policy, 11(1), pp. 17-29, 2004. 
[10] Liu, R., Pendyala, R.M.,and Polzin, S., Assessment of Intermodal Transfer Penalties Using Stated Preference Data. Transportation Research Record No.1607, pp. 74-80, 1997.

[11] Avineri, E. andPrashker, J.N., Violation of Expected Utility Theory in Route-Choice Stated Preference. Transportation Research Record, No. 1894, pp. 222-229, 2004.

[12] Andrade, K., Uchida, K.,and Kagaya, S., Development of Transport Mode Choice Model by Using Adaptive Neuro-Fuzzy Inference System. Transportation Research Record, No. 1977, pp. 8-16, 2006.

[13] Manju, V.S., Sajitha, M.,and Isaac, K.P. Analysis of Route Choice Behaviour of Bus Transit Users using Fuzzy Logic. 23rd ARRB Conference. Adelaide, Australia. pp. 1-8, 2008

[14] Ridwan, M., Fuzzy preference based traffic assignment problem. Transporation Research Part C, 12(3-4), pp. 209-233, 2004.

[15] Zadeh, L.A., Fuzzy Sets. Information and Control, 8(3), pp. 338-353, 1965.

[16] Teodorovic, D., Fuzzy Logic Systems for Transportation Engineering: The State of the Art. Transportation Research Part A, 33(5), pp. 337-364, 1999.

[17] Kahneman, D. and Tversky, A., Advances in Prospect Theory: Cumulative Representation of Uncertainty. Journal of Risk and Uncertainity, 5(4), pp. 297-323, 1992.

[18] Brandstatter, E., Kuhberger, A.,and Schneider, F., A Cognitive-Emotional Account of the Shape of the Probability Weighting Function. Journal of Behavioral and Decision Making, 15, pp. 79-100, 2002.

[19] Avineri, E., A cumulative prospect theory approach to passengers behavior modeling: waiting time paradox revisited. Intelligent Transportation Systems, 8, pp. 195-204, 2004.

[20] Van de Kaa, E.J., Applicability of an Extended Prospect Theory to Travel Behaviour Research: A Meta-Analysis. Transport Reviews, 30(6), pp. 771804, 2010.

[21] Ceder, A., Public Transit Planning and Operation: Theory, Modelling and Practice, ed. Butterworth-Heinemann. 2007, Oxford, UK: Elsevier.

[22] Avineri, E. andPrashker, J.N., Violation of Expected Utility Theory in Route-Choice Stated Preference. Transportation Research Record, 1894, pp. 222-229, 2004.

[23] Currie, G. andWillis, D. Melbourne bus rail interchange strategy. 22nd Australasian Transport Research Forum. Sydney, Australia. pp. 169-186, 1998

[24] Zhang, L. andPrevedouros, P.D., User perceptions of signalised intersection level of service using fuzzy logic. Transportmetrica, 7(4), pp. 279-296, 2011.

[25] Postorino, M.N. andVersaci, M., A Neuro-Fuzzy Approach to Simulate the User Mode Choice Behaviour in a Travel Decision Framework. International Journal of Modelling and Simulation, 28(1), pp. 64-71, 2008.

[26] Kikuchi, S. andMiljkovic, D., Use of Fuzzy Inference for Modeling Prediction of Transit Ridership at Individual Stops. Transportation Research Record, No. 1774, pp. 25-35, 2001. 